\title{
MULHER E EMPREENDEDORA: UM ESTUDO SOBRE O PERFIL DAS EMPREENDEDORAS PARTICIPANTES DO CREDIAMIGO EM DIAMANTINA- MG
}

\author{
Cristiana Lara Cunha ${ }^{1}$
}

\footnotetext{
${ }^{1}$ Universidade de São Paulo
} 


\section{MULHER E EMPREENDEDORA: UM ESTUDO SOBRE O PERFIL DAS EMPREENDEDORAS PARTICIPANTES DO CREDIAMIGO EM DIAMANTINA- MG}

\section{Resumo}

O presente artigo apresenta um estudo realizado com mulheres microempreendedoras clientes do Crediamigo na região de Diamantina-MG. O estudo teve como objetivo avaliar o perfil dessas empreendedoras tomadoras de crédito no programa na cidade, bem como o perfil dos empreendimentos criados por elas. Para tanto, realizou-se um survey com 64 respondentes na instituição pesquisada. Assim, observou-se que a classe social de parte das clientes pesquisadas difere do público para o qual o microcrédito é direcionado. Também, fica evidente a importância dessa fonte de renda para a manutenção familiar, bem como constatouse que grande parte das respondentes na maioria das vezes trabalhava sozinha. Houve a constatação também de que o microcrédito tem importante papel na vida das mulheres, uma vez que possibilita a melhoria em seus empreendimentos.

Palavras chave: Empreendedorismo, Mulher, Microcrédito, Microempreendimentos.

\section{Introdução}

O Brasil apresenta importantes problemas sociais que merecem atenção em destaque, como a questão da pobreza, que ainda assola diversas pessoas por todo o país. Na tentativa de sair da condição do desemprego e da pobreza, muitas pessoas recorrem ao autoemprego como mecanismo de sobrevivência e de geração de renda para si e para seus familiares.

De acordo com dados da Pesquisa Nacional por Amostra de Domicílios (PNAD), do Instituto Brasileiro de Geografia e Estatística (IBGE, 2016a) o número de desempregados do país chegou a 12 milhões de pessoas em setembro de 2016. Um dos motivos que levam pessoas a considerar uma atividade própria como solução de vida, segundo Bernhoeft (1996), é o desejo de romper com uma situação em que estejam insatisfeitas com seu momento de vida.

A partir deste contexto pode ser verificado, em grande parte do Brasil, inclusive nas regiões mais pobres, um número cada vez mais crescente de mulheres desamparadas, necessitando ter uma atividade de renda para a manutenção familiar. Dados do IPEA (2015a) mostram que em 2009 chegava a 22 milhões o número de mulheres identificadas como responsáveis por suas famílias. Já em 2014 este número passou para 27,7 milhões de mulheres, segundo relatório do IBGE (2016b).

Tradições culturais normalmente aliadas a uma sociedade centrada no gênero masculino fazem com que as mulheres sejam vistas em papéis sociais ligados ao lar e à família, como de mães e donas de casa (JONATHAN, 2005); pode fazer com que grande parte da população e dos governos ignorem a capacidade criativa e empreendedora que elas
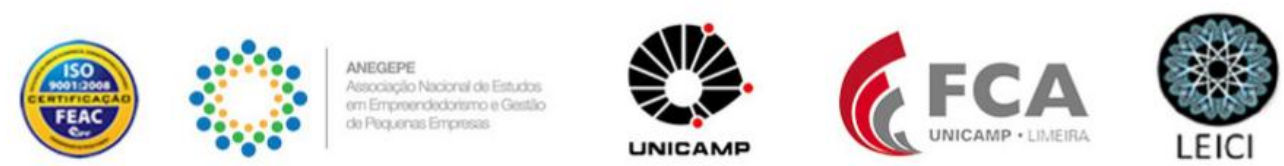
possuem. De acordo com Storbino e Teixeira (2014), o empreendedorismo não distingue gênero, apesar das primeiras definições existentes tratarem quase exclusivamente de homens.

A concessão de crédito tradicional, oferecida pela maioria dos bancos, não atinge todos os níveis sociais da população brasileira. Considerando a dificuldade em se obter garantias e os altos custos de um empréstimo, pessoas de poder econômico reduzido tendem a obter estes empréstimos através de familiares ou até mesmo através da figura de agiota (RIBEIRO; CARVALHO, 2006).

A criação de programas de microcrédito voltados para esta parcela menos favorecida da população é extremamente importante à medida que permite o acesso ao capital para a criação de um empreendimento próprio. Figueiredo (2010), afirma que a capacidade empreendedora é fator essencial para o desenvolvimento econômico. É neste contexto que se insere o caso do programa Crediamigo, criado pelo Banco do Nordeste (BNB), caso estudado nesta pesquisa.

O microcrédito, na concepção de Barone et al (2002) e Junqueira e Abramovay (2005), pode ser definido como uma modalidade de concessão de empréstimos em pequenas quantias a pessoas que desempenham alguma atividade de produção, mesmo que de baixa formalização e que não tenham acesso ao crédito de modo tradicional, devido, muitas vezes, à impossibilidade de dar garantias reais. De acordo com Yunus e Jolis(2003), um dos percussores do microcrédito, este não se trata de capital monetário, mas sim de capital humano, no sentido de que o grande objetivo do microcrédito é ajudar pessoas a atingirem seu potencial pleno.

Uma importante concepção pode ser observada ainda na ideia de Yunus e Jolis (2003) de que o microcrédito é bem mais que uma ferramenta geradora de renda; é também uma ferramenta de mudança social e uma maneira de dar novo significado à vida das pessoas, pois pode ser considerado um instrumento de integração social. O estudo da concessão de crédito para que as mulheres possam criar seus próprios empreendimentos está, portanto, não só aliado ao desenvolvimento da economia local, como também é uma solução para o desenvolvimento social.

Zeller e Sharma (1998), ao tratarem do impacto dos microfinanciamentos no contexto social, afirmam que o objetivo maior de tais operações é a melhoria na qualidade de vida da população economicamente menos favorecida. O microcrédito tem papel fundamental na promoção social, uma vez que dá a estas pessoas o acesso ao crédito produtivo, promovendo não só o desenvolvimento social e econômico, como também o pessoal, através de elevação na autoestima e no senso de empoderamento desta população.

O Crediamigo pode ser considerado o maior programa de microcrédito orientado da América do Sul e objetiva conceder crédito para pessoas economicamente desfavorecidas para a aquisição de materiais, suprimentos, ferramentas; para a abertura ou melhoria de seus empreendimentos e tem como objetivo facilitar o acesso de milhares de empreendedores, dos setores formal ou informal da economia, ao crédito (BNB, 2015). O setor informal é aquele dos trabalhadores que, segundo Fischer e Falconer (1998) e Ulyssea (2006), não contribuem pecuniariamente para a previdência social, sejam eles trabalhadores sem carteira de trabalho ou empreendores individuais.
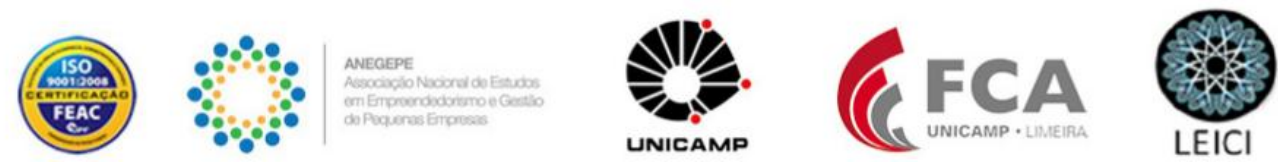
A relevância desta pesquisa se dá principalmente a partir questão da mulher, normalmente oprimida, aliada a práticas sexistas do setor financeiro. Este estudo ainda é de suma importância para o entendimento da realidade feminina de regiões mais pobres como o Vale do Jequitinhonha, local onde se insere a cidade estudada nesta pesquisa. $O$ empreendedorismo feminino se faz essencial, portanto, a fim de inserir estas mulheres marginalizadas na parcela de potenciais consumidores, movimentando a economia local, mas também ao colocá-las no papel de protagonistas: empreendedoras, microempresárias e detentoras de capital.

Assim, o objetivo geral do presente trabalho foi avaliar o perfil tanto das clientes tomadoras de microcrédito no Crediamigo Diamantina quanto de seus empreendimentos.

Levando em conta a importância dos trabalhos acerca dos temas tanto de empreendedorismo feminino quanto de microcrédito, faz-se necessário o estudo aqui contemplado. Esta pesquisa conta, além da introdução, com seções relativas ao referencial teórico, também com uma seção referente à metodologia da pesquisa, bem como uma sobre análise e discussão dos resultados, seguido, finalmente, pelas considerações finais.

\section{Referemcial Teórico}

\section{Empreendedorismo Feminino}

No contexto brasileiro, as mulheres vêm ocupando cada vez mais espaço no mercado de trabalho. Com a realidade econômica atual, grande parte da população feminina do país busca variar sua forma de sobrevivência, percorrendo atividades autônomas (NATIVIDADE, 2009). Segundo Jonathan (2005, p. 373), "o potencial econômico do empreendedorismo feminino brasileiro é bastante significativo", uma vez que os empreendimentos detidos por mulheres representam quase metade dos negócios, em ambos os setores formais e informais da economia.

A realidade empreendedora feminina, no entanto, perpassa os conceitos básicos do empreendedorismo. Disparidades de gênero são claramente visíveis neste campo e, portanto, fatores extremamente relevantes para a presente pesquisa. Segundo relatório de políticas sociais publicado pelo IPEA (2015b, p. 504) “[o] Estado brasileiro [é] responsável, por determinação constitucional, pela garantia de igualdade entre homens e mulheres e pelo combate a todas as formas de violência e opressão". A realidade, no entanto, mostra que ainda há diferenças entre os gêneros, e a mulher é comumente vista com papel único de mãe e dona de casa.

Jonathan e Silva (2007) afirmam que existe uma armadilha na "ideia de que as mulheres têm necessidades, inclinações e capacidades para cuidar e se ocupar do lar, ao passo que os homens têm habilidades fora do lar e para prover" (JONATHAN; SILVA, 2007, p.78). Infelizmente, a sociedade brasileira ainda é dotada de valores sexistas, conforme comprova pesquisa no relatório de políticas sociais do IPEA:

As pesquisas evidenciaram alguns aspectos do repertório de valores sexistas vigentes na sociedade brasileira, sobretudo daqueles que estão calcados na 
compreensão de que as mulheres devem ser controladas e vigiadas no cumprimento de papéis sociais de gênero bem delineados. (IPEA, 2015b, p. 506).

A falta de oportunidades no mercado, bem como a necessidade de estar alocada num posto de emprego para gerar renda fazem com que as mulheres brasileiras atuem "para manter sua sobrevivência, e isso se dá em grande escala pelo exercício profissional informal" (NATIVIDADE, 2009, p. 233). Apesar de a autora supracitada afirmar da preeminência do setor informal no país, a presente pesquisa não se ateve somente a este setor, sendo abrangente a ambos os setores.

Pesquisa realizada pelo GEM (2013) mostra que no Brasil 66,2\% das mulheres empreendedoras as são por oportunidade, enquanto que $33,8 \%$ delas as são por necessidade. Tal diferenciação pôde ser vista na seção anterior, na qual empreendedores por opção são aqueles que empreendem por vontade e vocação, enquanto que empreendedores por necessidade são aqueles que empreendem por não haver outra opção de sustento.

Além das barreiras nos âmbitos pessoais e familiares, as mulheres ainda enfrentam barreiras para se inserirem no mercado de trabalho, vendo então no empreendedorismo uma forma de provisão de sustento para si e suas famílias (FRANCO, 2014). Apesar destas barreiras, as mulheres buscam estabelecer um equilíbrio entre trabalho e família, o que reflete na característica feminina de multiplicidade de papéis (JONATHAN; SILVA, 2007).

Na visão de Bruni, Gherardi e Poggio (2004), são três as principais barreiras contra o empreendedorismo feminino. Em primeiro lugar vem o status sócio cultural da mulher, comumente vista num papel familiar e dotada de responsabilidades domésticas. Em seguida, o acesso à informação, na medida em que, em um grande número de países, as mulheres costumam ser banidas do acesso à mídia e a veículos de informação. Por fim, a dificuldade de acesso ao capital, na qual as mulheres são vistas por alguns como pessoas que não sabem lidar com o dinheiro.

A partir dos dados apresentados, ficam evidentes algumas das dificuldades apresentadas pela sociedade para a inserção das mulheres no mercado. Apesar disso, o número de mulheres empreendedoras vem se mostrando cada vez mais crescente. É neste sentido que se realça a utilidade deste estudo no campo empreendedor feminino.

\section{Microfinanças e Microcrédito}

La Torre e Vento (2006) definem as microfinanças como a oferta de um conjunto de serviços financeiros modestos dados à população economicamente menos favorecida. Dessa forma, as microfinanças são responsáveis, segundo Neri (2008), por servir àquelas pessoas excluídas das instituições financeiras tradicionais e têm como principal objetivo o de desenvolver tecnologias de forma que o provimento a estes clientes seja feito de forma sustentável.

O microcrédito é considerado uma peça do campo das microfinanças (NERI, 2008). A definição dada pelo autor supracitado às microfinanças mostra que estas se referem a serviços financeiros variados, nos quais estão inseridos o microcrédito, mas também as micropoupanças, crédito imobiliário, microsseguros, dentre outros.
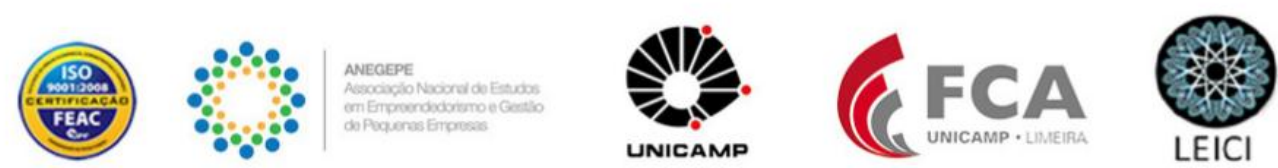
O microcrédito, conforme brevemente escrito em capítulo anterior, pode ser conceituado como uma modalidade de empréstimos de baixo valor destinado à produção e concedidos a empreendedores que não possuem acesso ao sistema tradicional de crédito (BCB, 2002). Segundo publicação do Banco Central, o microcrédito é uma ferramenta democratizadora e é parte essencial das políticas de desenvolvimento, uma vez que dispõe crédito para empreendedores de baixa renda (BCB, 2002).

Esta modalidade de concessão de crédito possui um impacto social reconhecido, contribuindo para resgate da cidadania, eleva autoestima e promove a inclusão (BCB, 2002). $\mathrm{O}$ microcrédito possui ainda potencial no combate à pobreza e tem importante papel de promover desenvolvimento econômico em comunidades carentes (SPOSTO et al; 2011).

Porém, o microcrédito como conhecido hoje, deve a atribuição de sua importância ao professor bengalês de economia Muhammad Yunus. Ele, que foi laureado pelo Prêmio Nobel da Paz em 2006, iniciou em 1976 um trabalho de concessão de empréstimos a pessoas pobres que moravam em uma aldeia próxima a sua casa, com o montante inicial de U\$27,00 dólares concedido para um grupo de 42 pessoas (YUNUS; JOLIS, 2003).

Mais tarde, Yunus fundou o banco conhecido como Grameen Bank, ou Banco dos Pobres, como é popularmente chamado. A ação de seu banco ajuda hoje milhões de pessoas pobres não só em Bangladesh, mas em vários países (BCB, 2002).

\section{A dimensão social do Microcrédito}

O avanço tecnológico permitiu, nos últimos anos, que a população normalmente excluída do acesso às instituições financeiras tradicionais passasse, então, a acessar o crédito (NERI, 2008). As três grandes dificuldades que esta parcela da população usualmente se esbarrava, segundo Gonzalez, Piza e Garcia (2009) eram: a) o elevado risco das operações; b) os altos custos de transação e c) a falta de garantias reais.

O microcrédito, portanto, se diferencia do crédito tradicional, primeiramente, pela metodologia de concessão, onde o primeiro promove um acompanhamento do cliente (a instituição financeira normalmente vai até o cliente), enquanto no último, o cliente assume uma postura reativa, quando ele vai até a instituição financeira. Ainda, tal diferenciação também se dá pela diferença na apresentação de garantias, pois na ferramenta do microcrédito o sistema de garantias está mais próximo da realidade social do tomador (BCB, 2002).

Neri (2008) considera o microcrédito uma solução do tipo 'ganha-ganha', na qual há benefícios tanto para os clientes quanto para as instituições financeiras. O microcrédito é, ainda, considerado por muitos como uma estratégia para solucionar o problema da pobreza. No entanto, Neri (2008) abranda tal afirmação, na medida em que mostra também a vantagem alcançada pelos bancos neste tipo de concessão de crédito, uma vez que assim estas instituições aumentam seu portfólio de clientes.

Quando da aplicação com sucesso das ferramentas do microcrédito, Neri (2008, p. 33) afirma que elas funcionam como "uma alavanca para a melhoria da renda e da condição de vida de seus clientes". O mesmo autor ainda afirma que o microcrédito é capaz de promover um choque capitalista na população pobre, uma vez que permite a ela acesso a capital produtivo, sendo este um possível meio de saída da condição da pobreza (NERI, 2008).
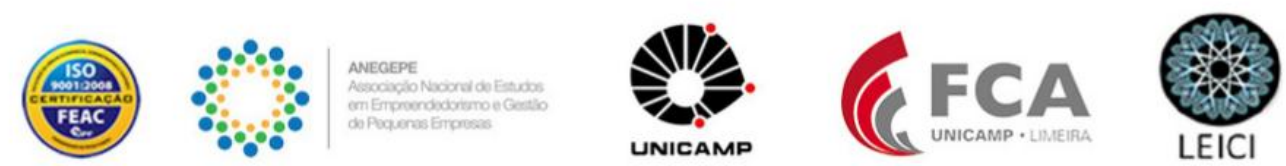


\section{O Foco nas Mulheres}

Apesar do visível viés sexista do sistema financeiro em geral (YUNUS; JOLIS, 2003), no microcrédito prefere-se emprestar dinheiro à mulher do que ao homem (GONZALEZ, PIZA, GARCIA, 2009). Para um programa de microcrédito, focar nas mulheres é considerado vantajoso.

Este enfoque no público feminino se dá em razão do papel que a mulher desempenha na família e na sociedade, e de acordo com Yunus e Jolis (2003, p. 117), "o dinheiro, quando utilizado por uma mulher numa família, beneficia mais o conjunto de membros do que quando é utilizado por um homem". O sexo feminino para Gonzalez, Pisa e Garcia (2009) é considerado mais prudente na administração dos recursos do que o sexo masculino.

Inúmeras pesquisas foram realizadas neste sentido, iniciadas por Muhammad Yunus e indicam que, quando o crédito é dado às mulheres, traz mudanças mais rápidas do que quando dado aos homens (YUNUS; JOLIS, 2003). Isto ocorre uma vez que mulheres destinam a renda primeiramente à alimentação e educação dos filhos, gerando um impacto social maior, enquanto homens tendem a satisfazer suas necessidades pessoais primeiro (NERI, 2008).

Uma vantagem trazida pelo enfoque neste público em particular perpassa por um âmbito mais pessoal, uma vez que é frequentemente retratado um aumento na autoestima destas mulheres empreendedoras (YETIM, 2008). Isto ocorre principalmente em países onde a disparidade entre os gêneros é gritante e onde o sistema é particularmente mais sexista.

A partir dos motivos acima expostos, é de suma importância ressaltar o microcrédito como "uma ferramenta de diminuição da desigualdade de renda entre os sexos" (NERI, 2008, p. 39). Porém, o avanço no processo de igualdade vai muito além do que só a renda. Uma vez que o microcrédito dá acesso às mulheres ao crédito produtivo, pode-se evidenciar a ocorrência do fenômeno conhecido como empoderamento feminino.

De acordo com Karl (1995), o empoderamento feminino pode ser entendido como um mecanismo de conscientização e capacitação da mulher, onde essa se ocupa de maior poder decisório, participação e controle em suas ações. Esta conscientização se relaciona à participação em decisões familiares, mas não somente, entrando também nos âmbitos políticos e sociais.

\section{Metodologia}

A presente seção apresenta a metodologia utilizada neste trabalho, a fim de alcançar o objetivo proposto por esta pesquisa. Para tanto, foi feito um Estudo de Caso, abordando o caso específico de mulheres micro empreendedoras tomadoras de crédito no programa do Banco do Nordeste, o Crediamigo, na região de Diamantina, no Vale do Jequitinhonha, em Minas Gerais. Segundo Gil (2002), esta é uma modalidade de pesquisa que consiste no desenvolvimento de um estudo com poucos objetos, mas de forma mais aprofundada, com o propósito de detalhar o conhecimento destes. A necessidade pelo desenvolvimento de pesquisas do tipo do estudo de caso vem, segundo Yin (2005, p. 20), "do desejo de se compreender fenômenos sociais complexos".
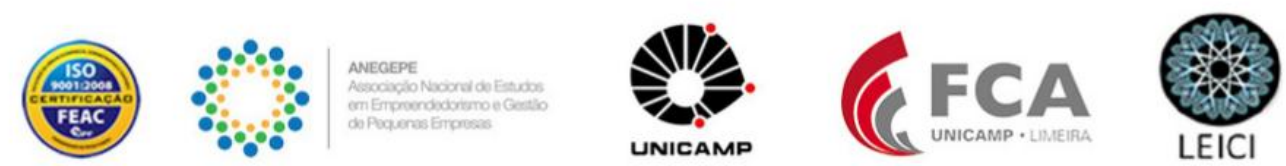
Quanto aos objetivos da pesquisa, pode-se classificá-la como de caráter descritivo. Segundo Gil (2002, p.42), pesquisas do tipo descritivas buscam primordialmente relatar as "características de determinada população ou fenômeno, ou então o estabelecimento de relações entre variáveis". Os estudos de caráter descritivo também têm como foco a intenção de conhecer "a comunidade, seus traços característicos, suas gentes, seus problemas" (TRIVIÑOS, 2013, p. 110), visto que a preocupação desta abordagem ainda apresenta uma atuação social prática.

Segundo Barros e Lehfeld (2009) a presente pesquisa definida como Estudo de Caso está ainda relacionada à coleta de dados e informações acerca de um ou mais casos ou situações particulares a fim de relatá-los bem como emitir algum parecer de acordo com as questões identificadas em sua realização. Nesta pesquisa as observações se relacionam à situação do microcrédito abordado, elas advêm de uma população que se define por todas as mulheres tomadoras de microcrédito, clientes atuais no programa Crediamigo do BNB, especificamente na região de abrangência da agência Diamantina.

Desta feita, utilizou-se a clássica fórmula de Stevenson (1981) representada na equação 1 para calcular o tamanho da amostra utilizada neste estudo. A agência estudada possuía uma população equivalente a 997 mulheres clientes à época do cálculo.

Em que:

$$
\eta=\frac{Z^{2} \cdot P \cdot Q \cdot N}{(N-1) \cdot e^{2}+P \cdot Q \cdot Z^{2}}
$$

Equação 1

$\eta=$ Tamanho da amostra

$\mathrm{Z}=$ Nível de confiança

$\mathrm{P}=$ Porcentagem de ocorrência do fenômeno

$\mathrm{Q}=$ Porcentagem complementar

$\mathrm{N}=$ População

$\mathrm{e}=$ Erro máximo permitido

Assim, utilizando-se de um nível de significância de $90 \%$ e um erro amostral de $10 \%$, chegou-se ao número amostral de 63,41 mulheres. Desta forma, os questionários foram aplicados para 64 mulheres, clientes da agência Diamantina do Crediamigo.

\section{Análise dos dados}

Nesta seção são analisados os dados coletados através dos questionários. Para tanto, a seção compõe-se da análise descritiva dos dados obtidos através das respostas das 64 clientes do Crediamigo Diamantina.

É importante ressaltar que, na análise descritiva das variáveis qualitativas utiliza-se as frequências absolutas e relativas, enquanto na análise descritiva das variáveis quantitativas utiliza-se medidas de posição, tendência central e dispersão.

Além disso, nas tabelas a seguir, considera-se a unidade $\mathrm{N}$ como o número de observações. Já a sigla D.P diz respeito ao desvio padrão, enquanto que a sigla 1Q diz respeito ao número de respostas que se encontram situadas antes do primeiro quartil, enquanto
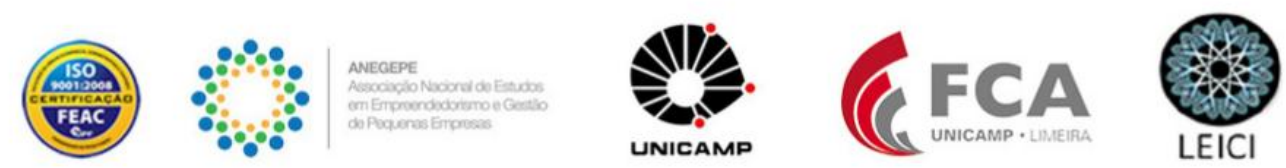
que $2 \mathrm{Q}$ diz respeito às respostas situadas antes do segundo quartil e, por fim, a sigla $3 \mathrm{Q}$ se refere às respostas situadas antes do terceiro quartil.

A Tabela 1 a seguir apresenta a análise descritiva das variáveis categóricas da amostra coletada em relação ao perfil das empreendedoras, correspondente às 64 clientes Crediamigo Diamantina respondentes.

Tabela 1 - Perfil das mulheres empreendedoras clientes do Crediamigo na cidade de Diamantina

\begin{tabular}{|c|c|c|c|}
\hline & Variáveis & $\mathbf{N}$ & $\%$ \\
\hline \multirow{4}{*}{ Município de residência } & Datas & 1 & $1,56 \%$ \\
\hline & Diamantina & 59 & $92,19 \%$ \\
\hline & Felício dos Santos & 2 & $3,13 \%$ \\
\hline & São João da Chapada & 2 & $3,13 \%$ \\
\hline \multirow{2}{*}{ Localização da residência } & Área Urbana & 58 & $90,63 \%$ \\
\hline & Zona Rural & 6 & $9,38 \%$ \\
\hline \multirow{4}{*}{ Estado Civil } & Casada / União estável & 38 & $59,38 \%$ \\
\hline & Separada / Divorciada & 9 & $14,06 \%$ \\
\hline & Solteira & 16 & $25,00 \%$ \\
\hline & Viúva & 1 & $1,56 \%$ \\
\hline \multirow{5}{*}{ Escolaridade } & Fundamental ou Básico (até a $8^{\mathrm{a}}$ série) & 23 & $35,94 \%$ \\
\hline & Médio ou Segundo Grau & 32 & $50,00 \%$ \\
\hline & Nunca estudei & 1 & $1,56 \%$ \\
\hline & Pós-Graduação & 1 & $1,56 \%$ \\
\hline & Superior (Faculdade) & 7 & $10,94 \%$ \\
\hline \multirow{2}{*}{$\begin{array}{l}\text { Principal responsável pela renda } \\
\text { familiar }\end{array}$} & Não & 47 & $73,44 \%$ \\
\hline & Sim & 17 & $26,56 \%$ \\
\hline \multirow{2}{*}{ Existe outra fonte de renda } & Não & 34 & $53,13 \%$ \\
\hline & Sim & 30 & $46,88 \%$ \\
\hline \multirow{6}{*}{ Classe } & A & 0 & $0,00 \%$ \\
\hline & B1 & 2 & $3,13 \%$ \\
\hline & $\mathrm{B} 2$ & 19 & $29,69 \%$ \\
\hline & $\mathrm{C} 1$ & 23 & $35,94 \%$ \\
\hline & $\mathrm{C} 2$ & 17 & $26,56 \%$ \\
\hline & $\mathrm{D}-\mathrm{E}$ & 3 & $4,69 \%$ \\
\hline \multirow{3}{*}{$\begin{array}{l}\text { Consulta anterior ao empréstimo } \\
\text { com o cônjuge }\end{array}$} & Não & 31 & $48,44 \%$ \\
\hline & Não possuo / não possuía cônjuge & 12 & $18,75 \%$ \\
\hline & Sim & 21 & $32,81 \%$ \\
\hline
\end{tabular}

Fonte: Elaborado com dados da pesquisa

Da tabela acima, pode-se verificar que, a respeito da unidade familiar, a maioria das respondentes reside no município de Diamantina, na área urbana. Mais da metade das 
respondentes são casadas ou estão em uma união estável. Metade das respondentes possuem, a respeito da escolaridade, ensino médio; cerca de $11 \%$ possuem nível superior; 35,94\% possuem ensino fundamental; e apenas $1,56 \%$ possuem pós graduação, sendo que este mesmo percentual corresponde também às respondentes que não possuem nenhum tipo de instrução escolar formal.

Em relação à renda familiar, considerando o Critério de Classificação Econômica Brasil (ABEP, 2015), nenhum indivíduo da amostra foi classificado como classe A, sendo que a grande maioria está entre as classes B1 e C2 e somente 4,69\% dos participantes se enquadram nas classes D-E. Tal classificação destoa do público alvo do microcrédito, uma vez que este busca atingir às camadas mais baixas da população. Por fim, no que diz respeito ao empréstimo tomado, observa-se que quase metade das respondentes não consultaram o cônjuge antes da tomada.

Já a tabela 2 a seguir diz respeito ao perfil dos empreendimentos criados pelas mulheres clientes do Crediamigo na cidade de Diamantina.

Tabela 2 - Perfil dos empreendimentos criados pelas mulheres clientes do Crediamigo na cidade de Diamantina

\begin{tabular}{|c|c|c|c|}
\hline \multicolumn{2}{|r|}{ Variáveis } & $\mathbf{N}$ & $\%$ \\
\hline \multirow{2}{*}{ A empresa é sua atividade principal } & Não & 16 & $25,00 \%$ \\
\hline & Sim & 48 & $75,00 \%$ \\
\hline \multirow{4}{*}{ Situação Jurídica } & Em processo de formalização & 3 & $4,69 \%$ \\
\hline & Formal & 27 & $42,19 \%$ \\
\hline & Informal & 14 & $21,88 \%$ \\
\hline & MEI- Microempreendedor Individual & 20 & $31,25 \%$ \\
\hline \multirow{6}{*}{$\begin{array}{l}\text { Número de pessoas que trabalham na } \\
\text { empresa }\end{array}$} & Apenas eu & 43 & $67,19 \%$ \\
\hline & 2 & 19 & $29,69 \%$ \\
\hline & 3 & 2 & $3,13 \%$ \\
\hline & Entre 4 e 20 & 0 & $0,00 \%$ \\
\hline & Entre 11 e 20 & 0 & $0,00 \%$ \\
\hline & Mais de 20 & 0 & $0,00 \%$ \\
\hline \multirow{5}{*}{ Local de funcionamento } & Ambulante & 2 & $3,13 \%$ \\
\hline & Ponto Comercial (loja ou sala) & 20 & $31,25 \%$ \\
\hline & Residência & 31 & $48,44 \%$ \\
\hline & Serviço à domicílio & 9 & $14,06 \%$ \\
\hline & Outro & 2 & $3,13 \%$ \\
\hline \multirow{4}{*}{ Tempo de negócio } & Menos de 1 ano & 7 & $10,94 \%$ \\
\hline & Entre 1 e 3 anos & 26 & $40,63 \%$ \\
\hline & Entre 3 e 5 anos & 16 & $25,00 \%$ \\
\hline & Mais de 5 anos & 15 & $23,44 \%$ \\
\hline \multirow{3}{*}{ Setor de atividade } & Agricultura Comercial & 1 & $1,56 \%$ \\
\hline & Agricultura de Subsistência & 1 & $1,56 \%$ \\
\hline & Artesanato & 5 & $7,81 \%$ \\
\hline Organizadores: & Realizadores: & & \\
\hline \multicolumn{4}{|l|}{ WFGV EAESP } \\
\hline
\end{tabular}




\begin{tabular}{llcc} 
& Comércio & 38 & $59,38 \%$ \\
& Indústria & 5 & $7,81 \%$ \\
& Prestação de Serviços & 14 & $21,88 \%$ \\
& Outro & 0 & $0,00 \%$ \\
\hline \multirow{3}{*}{ Motivo de começar o negócio } & Falta de emprego formal & 21 & $32,81 \%$ \\
& Oportunidade de negócios & 26 & $40,63 \%$ \\
& Complementação de renda & 47 & $73,44 \%$ \\
& Indicação de amigos ou familiares & 7 & $10,94 \%$ \\
& Uso de indenização por demissão & 0 & $0,00 \%$ \\
& Ocupação após a aposentadoria & 1 & $1,56 \%$ \\
& Outro/Gostar do que faço & 1 & $1,56 \%$ \\
\hline \multirow{2}{*}{$\begin{array}{l}\text { Separação da administração do } \\
\text { dinheiro do negócio e pessoal }\end{array}$} & Sempre & 41 & $64,06 \%$ \\
& Às vezes & 22 & $34,38 \%$ \\
\hline Fonte: Elabo & 1 & $1,56 \%$ \\
\hline
\end{tabular}

Fonte: Elaborado com dados da pesquisa

No que diz respeito às questões sobre a empresa/negócio, a maioria das respondentes tem a empresa como sua atividade principal. Este percentil corresponde a $75 \%$ das respondentes.

Também responderam que cerca de $73 \%$ das empresas eram formalizadas ou MEI, enquanto $21,88 \%$ afirmaram que seu negócio não possuía formalização. Nos empreendimentos pesquisados, a maioria empregava apenas um indivíduo $(67,19 \%)$.

Quanto à localização, cerca da metade das respondentes afirmaram que seu empreendimento era estabelecido em sua residência. Já $31,25 \%$ possuem ponto comercial (loja ou sala).

A grande maioria dos negócios se enquadra no setor de comércio ou serviços (81\%). Estes setores são considerados mais 'feminilizados' ao comparados aos demais. Em adição, 40,63\% afirmaram da duração de seu negócio entre 1 e 3 anos.

As motivações principais escolhida para iniciar o negócio foi a complementação de renda ou a falta de emprego formal. Já no que diz respeito à administração do dinheiro do negócio, 64\% afirmaram administrá-lo sempre separado do pessoal, enquanto $34 \%$ escolheram a 'opção às vezes'.

A partir dos dados acima apresentados, observa-se que a predominância dos setores de comércio e serviço, adicionado ao fato da maioria dos empreendimentos se localizarem na própria residência das respondentes, reforça o estereótipo de área normalmente focada pelo público feminino, sobretudo em relação a lojas de roupas, salões de beleza, estética e revenda de produtos de beleza.

Já a tabela 3 a seguir trata da análise descritiva das variáveis numéricas no que diz respeito ao perfil das respondentes. 
Tabela 3: Análise Descritiva das Variáveis Numéricas sobre o Perfil das Respondentes

\begin{tabular}{|c|c|c|c|c|c|c|c|c|}
\hline Variáveis & $\begin{array}{c}\mathbf{N} \\
\text { Válidos }\end{array}$ & Média & D.P. & Mín. & $1 Q$ & $2 Q$ & 3Q & Máx. \\
\hline Idade & 64 & 37,20 & 12,32 & 19 & 27,5 & 33,5 & 48,5 & 65 \\
\hline Número de Filhos & 64 & 2,27 & 1,57 & 0 & 1 & 2 & 3 & 6 \\
\hline $\begin{array}{l}\text { Número de filhos em } \\
\text { escolas públicas }\end{array}$ & 64 & 0,92 & 1,04 & 0 & 0 & 1 & 2 & 4 \\
\hline $\begin{array}{l}\text { Número de filhos em } \\
\text { escolas particulares }\end{array}$ & 64 & 0,00 & 0,00 & 0 & 0 & 0 & 0 & 0 \\
\hline
\end{tabular}

Fonte: Elaborado com dados da pesquisa

Sobre a tabela (3) acima, ressalta-se que o perfil das mulheres respondentes, que tem em média 37,20 anos. A menor idade apresentada por uma respondente foi de 19anos; e a maior igual a 65 .

Elas ainda possuem número médio de filhos igual a 2,27, com desvio padrão de 1,57. A média de filhos matriculados em escolas públicas é de 0,92 , sendo que nenhum está matriculado em escolas particulares.

As análises dos dados possibilitam identificar o perfil típico das mulheres empreendedoras clientes do Crediamigo na cidade de Diamantina. Possibilitaram, também, identificar o perfil dos empreendimentos por elas criados.

\section{Considerações Finais}

Esta pesquisa teve como objetivo principal avaliar o perfil das tomadoras de crédito no Crediamigo Diamantina, bem como o perfil de seus empreendimentos. Assim, selecionou-se 64 mulheres microempreendedoras, tomadoras de crédito pelo programa do Crediamigo na agência de Diamantina do Banco do Nordeste, para responder às questões presentes no Survey aqui proposto.

A partir dos dados observados nesta pesquisa, define-se o perfil das entrevistadas, como era esperado, de moradoras do município de Diamantina e região. Ainda, existe o predomínio de moradoras das áreas urbanas, com idade média de 37 anos.

Estas mulheres eram, em sua maioria, casadas ou em união estável, apresentando, majoritariamente, ensino escolar concluído até o ensino médio. A maioria não se considerou a principal responsável pela renda familiar, salientando o papel do homem como provedor principal da família.

No entanto, a maioria afirmou não ter consultado o cônjuge antes de pegar o empréstimo. Tal resposta pode significar certa mudança em algumas atitudes sexistas enraizadas na sociedade, como é comum ver em famílias brasileiras o homem ter controle sobre todo o dinheiro gerado pelo núcleo familiar. Esta resposta mostra ainda atitude proativa dessas mulheres, uma vez que estas tomam as rédeas de suas vidas financeiras, podendo isto gerar impacto em muitos outros âmbitos de suas vidas.

Pôde ser constatado ainda que a maioria possuía seu microempreendimento como atividade principal, em situação formal. As áreas dos empreendimentos eram, sobretudo, de
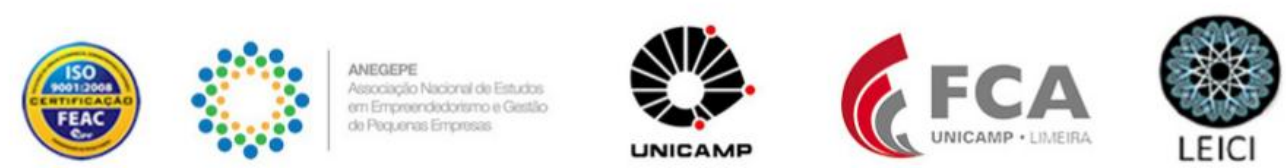
comércio ou serviços, localizados majoritariamente na residência das microempreendedoras. Ademais, constatou-se que a maioria das respondentes trabalhava sozinha em seu negócio, uma vez que cerca de $70 \%$ das entrevistadas responderam trabalharem apenas elas no empreendimento.

Observou-se, ainda, a predominância de respondentes pertencentes às classes econômicas B2 e C1, apesar deste ter sido criado para focar nas parcelas mais baixas da população. Estas respostas podem significar que o microcrédito falha ao tentar chegar às camadas mais necessitadas da população. No entanto, isto não invalida a importância de seu alcance para com aquelas mulheres atendidas.

Também se pôde perceber que a maioria das respondentes não possuía outra fonte de renda, além daquela proveniente dos microempreendimentos abarcados pelo programa do Crediamigo. Ficando evidente a importância dessa fonte de renda para a manutenção dos seus lares, sua condição de vida e de suas famílias, ainda que o homem fosse considerado o principal provedor financeiro da família.

Observa-se que o microcrédito tem importante papel na vida das mulheres, uma vez que possibilita a melhoria em seus empreendimentos. Assim criando impactos não só no âmbito profissional, como também familiar e pessoal. Bem como evidencia-se o acesso ao crédito como possibilitador de inúmeras mudanças na vida dessas microempreendedoras.

Em suma, enfatiza-se aqui a importância do microcrédito para estas mulheres pesquisadas e seus empreendimentos. A população de baixa renda, normalmente excluída do cenário bancário tradicional é, então, abraçada pelo instrumento do microcrédito. A somar o caso específico feminino, mostrou-se ainda mais importante este instrumento de crédito aqui estudado.

\section{Referências}

ASSOCIAÇÃO BRASILEIRA DE EMPRESAS DE PESQUISA- ABEP. Alterações na aplicação do Critério Brasil. ABEP. 2015

BARONE, F. M. et al. Introdução ao microcrédito. Brasília: Comunidade Solidária, 2002.

BARROS, A. J. S., LEHFELD, N. A. S. Fundamentos de Metodologia científica. 3 ed. São Paulo: Pearson Prentice Hall, 2007.

BERNHOEFT, R. Como tornar-se empreendedor em qualquer idade. São Paulo: Nobel, 1996.

BANCO CENTRAL DO BRASIL, BCB. Introdução ao Microcrédito. Brasília, Conselho da Comunidade Solidária. 65 p. 2002.

BANCO DO NORDESTE, BNB. O Crediamigo. Disponível em: <http://www.bnb.gov.br/crediamigo>. Acesso em 2 jun. 2015.
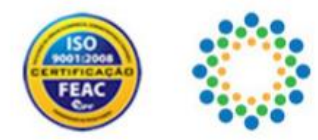
BRUNI, A., GHERARDI, S., POGGIO, B. Entrepreneur-mentality, gender and the study of women entrepreneurs. Journal of Organizational Change Management. v. 17, n. 3, p. 256268, 2004.

FIGUEIREDO, E. Mobilidade intergeracional de renda no Brasil. Nova Economia. v.20, n. 3, p. 427-455, set./dez., 2010.

FISCHER, R. M.; FALCONER, A. P. Desafios da parceria governo e terceiro setor. Revista de Administração (São Paulo). v.33, n.1, p.12-19, jan./mar., 1998.

FRANCO, M. M. S. Empreendedorismo feminino: características empreendedoras das mulheres na gestão das micro e pequenas empresas. VII Encontro de Estudos em Empreendedorismo e Gestão de Pequenas Empresas (EGEPE). Goiânia. Março, 2014.

GEM- Global Entrepreneurship Monitor. Empreendedorismo no Brasil. Relatório Executivo 2013. Publicado pelo IBQPPR/SEBRAE Nacional. 2013.

GIL, A. C. Como elaborar projetos de pesquisa. 4 ed. São Paulo: Atlas, 2002.

GONZALEZ, L., PIZA, C., GARCIA, D. Sinergia entre Microsseguro e Microcrédito e o Crescimento dos Mercados no Brasil. Revista Brasileira de Risco e Seguro (Online), v. 5, p. 29-54, 2009.

IBGE. Instituto Brasileiro de Geografia e Estatística. Pesquisa Nacional por Amostra de Domicílios. Disponível em: <http://www.ibge.gov.br/home/estatistica/indicadores/trabalhoerendimento/pnad_continua/>. Acesso em: 29 de novembro de 2016a.

IBGE. Instituto Brasileiro de Geografia e Estatística. Síntese de Indicadores Sociais. Disponível em: < http://biblioteca.ibge.gov.br/visualizacao/livros/liv95011.pdf >. Acesso em: 30 de novembro de 2016 b.

IPEA. Instituto de Pesquisa Econômica Aplicada. Aumenta o número de mulheres chefes de família. Disponível em: <http://www.ipea.gov.br/portal/index.php?option=com_content\&view=article\&id=6055>. Acesso em: 13 de novembro de 2015a.

IPEA. Instituto de Pesquisa Econômica Aplicada. Relatório de Políticas Sociais. Brasília, $2015 b$.

JONATHAN, E. G.. Mulheres empreendedoras: medos, conquistas e qualidade de vida. Psicologia em Estudo. Maringá, v. 10, n. 3, p. 373-382, set./dez. 2005. 
JONATHAN, E. G., SILVA, T. M. R.. Empreendedorismo Feminino: tecendo a trama de demandas conflitantes. Psicologia \& Sociedade. v. 19, n. 1, p.77-84, jan./abr. 2007.

JUNQUEIRA, R. G. V. ABRAMOVAY, R. A sustentabilidade das microfinanças solidárias. Revista de Administração (São Paulo). v. 40, n. 1, p. 19-33, jan./mar., 2005.

KARL, M. Women and Empowerment: Participation and Decision Making. Women and World Development Series. Londres: Zed Books, 1995.

LA TORRE, M., VENTO, G. A. Microfinance. Nova York. Editora Macmillan, 2006.

NATIVIDADE, D. R. Empreendedorismo feminino no Brasil: Políticas públicas sob análise. RAP- Revista de Administração Pública. v. 43, n. 1, p. 231-256; Jan./Fev. 2009.

NERI, M. C. Microcrédito: O mistério Nordestino e o Grameen Brasileiro: perfil e performance dos clientes do Crediamigo. Rio de Janeiro: FGV, 2008.

RIBEIRO, C. T.; CARVALHO, C. E. Do microcrédito às microfinanças: desempenho financeiro, dependência de subsídios e fontes de financiamento: uma contribuição a análise da 'experiência brasileira'. São Paulo: EDUC, 2006.

SPOSTO, A. S., ANTÃO, R. A. S., FARIAS, T. M., CAMPANHOLO, T., FONTES, G. G. O.. A utilização do microcrédito no desenvolvimento sustentável. Revista da Católica. v. 3, n.5, p. 27-34, jan./jul. 2011.

STEVENSON, W. J. Estatística aplicada à administração. São Paulo: Harbas, 1981.

STROBINO, M. R. de C; TEIXEIRA, R. M. Empreendedorismo feminino e o conflito trabalho-família: estudo de multicasos no setor de comércio de material de construção da cidade de Curitiba. Revista de Administração (São Paulo). v. 49, n. 1, p. 59-76, mar. 2014

TRIVIÑOS, A. N. S. Introdução à pesquisa em ciências sociais: A pesquisa qualitativa em educação. 1 ed, São Paulo: Atlas, 2013.

ULYSSEA, G. Informalidade no mercado de trabalho brasileiro: uma resenha da literatura. Revista de Economia Política. v.26, n. 4, p. 596-618. Out./Dez. 2006.

YETIM, N. Social Capital in Female Entrepreneurship. International Sociology. v. 23, n. 6. p. $864-885.2008$

YIN, R. K. Estudo de Caso: Planejamentos e Métodos. 3 ed. Porto Alegre: Bookman, 2005.

YUNUS, M.; JOLIS, A. O banqueiro dos pobres. São Paulo: Ática, 2003.
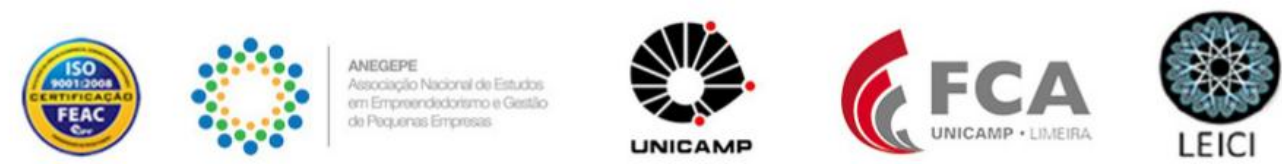
ZELLER, M.; SHARMA, M. Rural finance and poverty alleviation. Food Policy Report. Washington. 1998. Disponível em: 〈https://ideas.repec.org/p/fpr/fprepo/8.html〉. Acesso em: 16 de janeiro de 2016. 